\title{
Opportunistic Insights into Occupational Health Hazards Associated with Waterpipe Tobacco Smoking Premises in the United Kingdom
}

\author{
Ali Al-Bakri' ${ }^{1}$,Mohammed Jawad ${ }^{2}$, Pascale Salameh³, Mustafa al'Absi ${ }^{4}$, Saba \\ Kassim $^{1 *}$
}

\begin{abstract}
Background: Smokefree laws aim to protect employees and the public from the dangers of secondhand smoke. Waterpipe premises have significantly increased in number in the last decade, with anecdotal reports of poor compliance with the smokefree law. The literature is bereft of information pertaining to waterpipe premise employees. This study aimed to opportunistically gather knowledge about the occupational health hazards associated with working in waterpipe premises in London, England. Materials and Methods: Employees from seven convenience-sampled, smokefree-compliant waterpipe premises in London were observed for occupational activities. Opportunistic carbon monoxide (CO) measurements were made among those with whom a rapport had developed. Observations were thematically coded and analysed. Results: Occupational hazards mainly included environmental smoke exposure. Waterpipe-serving employees were required to draw several puffs soon after igniting the coals, thereby providing quality assurance of the product. Median CO levels were $27.5 \mathrm{ppm}$ (range $21-55 \mathrm{ppm}$ ) among these employees. Self-reported employee health was poor, with some suggestion that working patterns and smoke exposure was a contributory factor. Conclusions: The smokefree law in England does not appear to protect waterpipe premise employees from high levels of $\mathrm{CO}$. Continued concerns surrounding chronic smoke exposure may contribute to poor self-reported physical and mental wellbeing.
\end{abstract}

Keywords: Waterpipe - carbon monoxide - smoking - health policy - privileged access interviewers - United Kingdom

Asian Pac J Cancer Prev, 16 (2), 621-626

\section{Introduction}

Waterpipe smoking, a tobacco consumption method traditionally associated with the Middle East and South Asia, has increased in prevalence in the last decade in Europe and the US, especially among young people (Amin et al., 2010; Al-Naggar; Saghir, 2011; Martinasek et al., 2011). The waterpipe apparatus consists of a head, body, bowl and hose. The head is loaded with a 10-20 gram of fruit-flavoured tobacco mixture and often covered with perforated aluminium foil. Burning coal is placed on top of this foil, heating the underlying tobacco. When users inhale on the hose, a tobacco and coal smoke mixture passes through water, cooling the smoke before inhalation (Knishkowy and Amitai, 2005).

The flavoured and cooled tobacco smoke is one of many explanations for the rise in waterpipe tobacco smoking (Akl et al., 2013). However, studies have shown that waterpipe smokers may be exposed to high levels of toxicants, including nicotine (inducing dependence), tar and heavy metals (which are carcinogenic) and carbon monoxide (causing poisoning acutely and heart disease chronically) (Eissenberg and Shihadeh, 2009; Akl et al., 2010; Shihadeh et al., 2012; Hammal et al., 2013; Kassim et al., 2014).

Resultantly, calls have been made for increased legislative attention towards waterpipe tobacco smoking in some countries. However, in the US and Canada, many states and regions have exempted waterpipe tobacco smoking from smokefree laws, despite waterpipe premises exhibiting poorer air quality than areas where cigarettes were permitted (Noonan, 2010; Cobb et al., 2013, Hammal et al.,2013). The United Kingdom witnessed over a $200 \%$ rise in waterpipe premises between 2007 and 2012 (British Heart Foundation (BHF, 2012), and London alone has over 400 known waterpipe premises (Jawad, 2014). There is little evidence to suggest that industry growth is slowing, as shown by a recent survey among young people which showed waterpipe tobacco smoking to be three times more prevalent than cigarette smoking (Jawad et al., 2013). 
England is one of many countries which has not exempted waterpipe tobacco smoking from its smokefree law, implemented in 2007. This law was passed with the intention to protect the public and staff from the dangers of indoor secondhand smoke (Action on Smoking and Health (ASH, 2011). However, anecdotal reports in England and elsewhere suggest that waterpipe premises' compliance with the smokefree law is poor (Deshpande et al., 2010; Raute et al., 2011; Jawad, 2014), potentially jeopardising the health of the public and staff in these premises (King et al., 2011; Zulkifli et al., 2014). No studies to date have explored the occupational health hazards of waterpipe premise employees, despite the increasing number of premises and supposedly poor compliance with tobacco control legislation.

\section{Materials and Methods}

\section{Design, setting and waterpipe premises recruitment}

The original, primary objective of this study was to assess waterpipe tobacco dependence and identify factors associated with dependence among patrons (customers) in waterpipe premises, the methodology and ethical approval of which is described in detail elsewhere (Kassim et al., 2014). Waterpipe premises are defined as commercial businesses where waterpipe tobacco smoking occurs onsite. These include 'waterpipe cafes', where waterpipe smoking is the main trade, but also restaurants that serve waterpipe as an ancillary service. The research area was the City of Westminster, a small and central borough/district in London, United Kingdom. The City of Westminster has the highest number and density of known waterpipe premises in the United Kingdom $(n=110,5.1$ waterpipe premises $/ \mathrm{km}^{2}, 5.0$ waterpipe premises $/ 10,000$ residents) (Jawad, 2013b).

Between October 2011 and November 2011, waterpipe premises from two main roads in the area were approached to participate in this study. Of 22 approached premises, seven consented to participate, all of which declared to be compliant with the smokefree law. A weekly random timetable was created and they were visited by one researcher $(\mathrm{AAB})$ who was of the same ethnicity and spoke the same language as most of the waterpipe premise employees i.e. a privileged researcher (Griffiths et al., 1993).

\section{Data collection}

For the primary study, data collection was concentrated on surveying patrons to identify waterpipe dependence and taking their carbon monoxide $(\mathrm{CO})$ readings using the piCO Smokerlyzer ${ }^{\circledR}$ Bedfont Scientific (Kassim et al., 2014). During this time, the privileged researcher was able to observe and informally interact with waterpipe premise employees. The privileged researcher collected data on waterpipe premise employees by exercising a qualitative methodology known as participant observation. This is where a researcher interacts with a group of individuals through an involvement in their cultural environment. It particularly useful for understanding newly formed groups, where important differences may exist between the view of insiders as opposed to outsiders (Jorgensen, 1989).
Waterpipe premises fit these criteria based on the fact they are a newly formed, proliferating industry (Rastam et al., 2004) with suggestions of the development of an "underground culture" among staff and poor engagement with local government (Jawad, 2014).

\section{Interview and transcript analysis}

The privileged researcher $(\mathrm{AAB})$ reflected on his interactions with waterpipe premise employees and was subsequently interviewed by another researcher (MJ) to explore these interactions and extract further details. This semi-structured interview used a mixture of open and closed questions and lasted approximately 60 minutes. Questions centred around four main domains: $i$ ) the privileged researcher's actions in waterpipe premises ii) the physical environment of waterpipe premises iii) analytical description of employees who were observed and $i v$ ) the employees' actions and conversations in waterpipe premises.

The interview was audio recorded and accurately transcribed, ready for qualitative analysis. A framework approach was used to derive themes deductively, and cross-index concept coding occurred manually (Hsieh and Shannon, 2005). Derived themes were cross-checked by the interviewee before finalisation. Three main themes were elicited: cultural barriers to participation, occupational hazards and the physical and mental wellbeing of waterpipe-serving employees. Quotes throughout this manuscript are taken from the interview between two the two researchers (AAB and $\mathrm{MJ}$ ). No audio recording occurred at the waterpipe premises.

\section{Results}

Over the course of one month, the researcher spent approximately 180 hours in seven waterpipe premises. Of these seven, two were recruited by normal mapping and five were recruited through private contacts or patrons with whom a strong rapport had been developed.

\section{Theme One: Cultural barriers to participation}

Waterpipe premises in the City of Westminster were almost exclusively run by Arabic-speaking employees from Middle Eastern backgrounds. Most of these knew little English. Traditional Arabic dishes were seen to be served and patrons sat in an atmosphere decorated with Arabic furnishings. Arabic music and television, mainly showing sport, were heard and seen in the background. While this posed no direct barrier to the privileged researcher, who was of the same culture and spoke Arabic fluently, it emphasised the cultural embodiment of waterpipe premises, and the need to be aware of cultural norms when engaging with employees.

The importance of culture was noted on several interactions with waterpipe premise managers. Permission to use waterpipe premises as a research area was only granted on the basis that the researcher was from the same culture and spoke the same language as the managers, and more often than not, also on the basis that the researcher and manager had a mutual contact for recommendation. Even then, the privileged researcher felt that reluctance 
Opportunistic Insights into Occupational Health Hazards Associated with Waterpipe Tobacco Smoking Premises in the UK

was only overcome by the fact that pity was taken on him for being a student who had recently arrived from the Middle East.

"To be honest, I don't know how I managed to get seven [waterpipe premises to participate in the study]. I think some of them felt sorry for me because I told them I was a student from Iraq, planning to go back after this project."

Furthermore, culture played an important role in understanding the relationship between waterpipe premise managers and other agencies, such as local authorities. There was a distinct feeling that local government enforcement of tobacco legislation was an attack on the Middle Eastern culture. A sense of animosity was perhaps mainly driven by fear of losing their business and hence losing the ability to express their culture.

This feeling extended to university-led engagement with waterpipe premises. While formal participant information sheets and recruitment letters helped earn the privileged researcher a formal or official status among the primary research participants (the patrons), it was also detrimental to the overall recruitment process in some cases. For example, one premise that was recruited through help of a private contact refused any further participation in the study after the premise manager caught hold of a recruitment letter intended for his customers. This resulted from what was perhaps a misunderstanding of the British, academic culture.

"I showed him [the customer] the [participant information] letter which was signed by my supervisor. The owner then jumped, ran towards me, took the letter from my hand and read it. He said "Sorry there will be no more data collection." I asked him why, and what was going on. He said "This happened to me before and it created a problem. You are here to create problems and I do not want you in my cafe."

\section{Theme Two: Occupational hazards}

Waterpipe premise employees were of two main types: food-serving and waterpipe-serving. This analysis focuses mainly on the latter, who were exclusively tasked with preparing the waterpipe, serving it to patrons, replenishing coals once they cooled and cleaning the apparatus. Several occupational hazards were observed among waterpipeserving employees.

The clearest occupational hazard was the high exposure to environmental tobacco smoke, despite premises' compliance with the smokefree law. While the main source was second-hand smoke emitted from patrons, it was compounded by two unique aspects of waterpipe-serving employees' responsibilities. The first was that waterpipes were always ignited in small, enclosed areas and sometimes in premise basements. The second was that waterpipe-serving employees had a responsibility to ignite and sample the waterpipe prior to its delivery to the customer (known as 'opening the shisha'). In practical terms, waterpipe-serving employees would draw several puffs soon after they ignited the coals, thereby providing quality assurance of the product.

"The problem is that regular customers are more likely to be dependent on waterpipe and staff have to open the shisha for them every day as a way of caring for their customers. I have also noticed that some customers would choose a special person to open the shisha for them saying "can you please open the shisha for me, you do it really well."

A rapport was built with several waterpipe premise employees while data collection occurred among their customers. As such, several employees from three main premises volunteered to have $\mathrm{CO}$ readings during their shift. These are presented in Table 1 and all employees were non-smokers of cigarettes. The median $\mathrm{CO}$ and $\mathrm{COHb}$ readings for six waterpipe-serving employees were $27.5 \mathrm{ppm}$ (range 21-55ppm) and 5.1\% (range 4.0-9.4\%), respectively. The median $\mathrm{CO}$ and $\mathrm{COHb}$ readings for three food-serving employees were 4ppm (range 2-6ppm) and $1.2 \%$ (range $2-6 \%$ ), respectively.

Other occupational hazards included the lack of gloves or masks worn when manually packing the waterpipe apparatus head with tobacco. Additionally, waterpipeserving employees would often be seen walking between tightly-enclosed seating arrangements whilst carrying a coal-holder containing burning coal. Coal would be knocked to the floor at times, usually by patrons. Finally, whilst holding a coal-holder containing burning coal, waterpipe-serving employees would be seen dangerously spinning the coal-holder in a circular rotational movement in an attempt to keep the coals hot.

"Since they are allowed to only smoke shisha outside, this means they have really small space for smoking and everyone sits beside each other. Sometimes if you have 3 or 4 people and everyone orders a shisha and puts it in the floor, there will be very limited space."

Theme Three: Physical and mental well-being of waterpipe-serving employees

Informal discussion with waterpipe premise employees led to the discovery of occupational physical and mental health problems. Physical health problems appeared to result from chronic smoke exposure, such as breathing difficulties and coughing. One waterpipe-serving employee, whose $\mathrm{CO}$ reading was $28 \mathrm{ppm}$, described how his health dramatically deteriorated since arriving from the Middle East to work in the United Kingdom. He was originally active and athletic, however since working in a waterpipe premise he explained how he had difficulty breathing and could barely run. He also described joy and relief at quiet work shifts, as he would not be overly tasked with preparing waterpipes for patrons and therefore

Table 1. Exhaled $\mathrm{CO}$ and $\mathrm{COHb}$ among Waterpipe Premise Employees in Three Premises

\begin{tabular}{cccc}
\hline Waterpipe premise & Employee type & $\mathrm{CO}(\mathrm{ppm})$ & $\mathrm{COHb}(\%)$ \\
\hline 1 & Waterpipe-serving & 24.0 & 4.5 \\
& Waterpipe-serving & 27.0 & 5.0 \\
& Food-serving & 6.0 & 1.6 \\
2 & Waterpipe-serving & 55.0 & 9.4 \\
& Waterpipe-serving & 42.0 & 7.4 \\
\multirow{2}{*}{3} & Food-serving & 2.0 & 0.8 \\
& Waterpipe-serving & 28.0 & 5.1 \\
& Waterpipe-serving & 21.0 & 4.0 \\
& Food-serving & 4.0 & 1.2 \\
\hline *CO, carbon monoxide; COHb, carboxyhaemaglobin; ppm, parts per million
\end{tabular}


be exposed to less smoke. Another employee was advised to visit his General Practitioner for general breathing difficulties.

Mental health problems appeared to result from stress of shift-pattern work, and the general socioeconomic status of the workers. All workers were young, male and mainly Arabic-only speaking. Many had recently immigrated to the United Kingdom. Although not formally recorded, shifts appeared to last for 10-12 hours. There appeared to be low educational attainment -and pay was described as substandard. One worker explained how he earned $£ 30$ for a 10 hour shift. The researcher recalls one conversation with a waterpipe-serving employee

"Dr, if you want to do research, please do research on us [waterpipe premise employees]. We have lots of difficulties, mainly financial ones because our payment is not good, and we always work with smoke. I sometimes feel scared when I think about my future in 20 years and how this smoke will affect my health".

These shift patterns led some employees to believe they were caught in a circle where low pay meant they had limited development options such as completing educational and language courses and other avenues for professional development.

\section{Discussion}

Main findings This study provides the first insight into the occupational health of waterpipe premise employees. Premises are deeply cultural environments and this may explain the sensitive relationship between premise owners and other agencies such as local government and academic institutions. The presence of a privileged researcher still resulted in two thirds of premises rejecting participation, and it is likely that future health surveillance among waterpipe premise employees will be challenging.

From what was observed, waterpipe premise employees involved in preparing and serving waterpipe were constantly exposed to large volumes of smoke and had high CO readings. This is in spite of premises' compliance with the smokefree law; a law designed to protect employees and the public from the dangers of secondhand smoke. An important finding was the fact that employees are tasked to take puffs from the waterpipe soon after ignition. Employees described physical and mental health issues related to smoke exposure and stressful work requirements, respectively. This poses a public health concern considering the proliferation of the waterpipe tobacco industry.

Previous research Although no studies to our knowledge have measured CO levels among waterpipe premise employees, a plethora of recent studies have measured CO levels among patrons in waterpipe premises, also indicating high levels. For example, median $\mathrm{CO}$ levels among 167 patrons in US waterpipe premises (where waterpipe premises are exempt from smokefree laws) were $24 \mathrm{ppm}$, and nearly $20 \%$ had CO levels above $51 \mathrm{ppm}$ (Barnett et al., 2011). These levels are similar to our findings (median 27.5ppm), although in contrast our study's employees were meant to be under the "protection" of the smokefree law. In Germany, continuous atmospheric
CO levels were measured over a four hour period in a room where waterpipe tobacco smoking was taking place, and levels peaked at almost 70ppm and had a median of 51ppm (Fromme et al., 2009).

High CO levels among waterpipe-serving employees may be explained by chronic secondhand smoke exposure during shifts, but also by the fact that they are required to ignite the waterpipe in small rooms and take puffs from it soon after ignition to test for product quality. Among laboratory studies of waterpipe smokers, it appears that the increase in $\mathrm{COHb}$ is greatest within the first five minutes of smoking than at any other time of a standard 45 minutes session (Eissenberg and Shihadeh, 2009). Furthermore, the number of smoke particles in smoke aerosol produced during the early minutes after ignition appear to be greater than at any other time of smoking (Monn et al., 2007). The health outcomes of inhaling this type of smoke composition are currently unknown and warrants further research attention. Also noteworthy is the risk of infection transmission from sharing waterpipes (Munckhof et al., 2003), of which employees are also liable to should they sample the waterpipe prior to delivering it to the customer.

In the US, both waterpipe premise smoking and nonsmoking rooms have higher mean PM2.5 (a marker of poor air quality) than premises where cigarette smoking is permitted indoors (Cobb et al., 2013). Poor air quality also exists in Canadian premises where "herbal" (non-tobacco) waterpipe is consumed; again worse than venues where cigarette smoking is permitted (Hammal et al., 2013). An "underground" culture appears to be present in countries such as Pakistan and India, where "crackdowns" on the industry by the police is a result of poor compliance (Jawad, 2013a). Although not witnessed in this study, the UK has had several reports of poor health and safety records with waterpipe premises. Examples include dropping burning coals onto flammable furniture (Jawad, 2014), explosions resulting from heating coals with gas bottles (BBC News Lancashire, 2011) and acute CO poisoning among patrons (Clarke et al., 2012).

Strengths and limitations This study has several limitations, mainly as a result of its opportunistic design. Convenient sampling of both premises and their employees is likely to lead to selection bias. Indeed, in contrast to our sample, most waterpipe premises in London are reported as non-compliant with the smokefree law (Jawad, 2014), and we hypothesise that occupational health hazards are greater in non-compliant venues. There was no systematic approach in $\mathrm{CO}$ measurements of employees, such as gathering demographic data, documenting precise shift patterns, recording the number of ignited waterpipes or the number of puffs taken. However, these preliminary data provide unique and important insights into the untouched area of waterpipe industry occupational health, and paves the way for addressing these points in future research.

Policy implications The main implication for this study is to consider the effect of the smokefree law on the protection of waterpipe premise employees. Smokefree laws may be generic in its application to any form of smoked tobacco or tobacco substitute (as is seen in England), however health policy should seek to contain waterpipe-specific recommendations should countries 
Opportunistic Insights into Occupational Health Hazards Associated with Waterpipe Tobacco Smoking Premises in the UK

display a significant presence of waterpipe premises. For example, preparation and ignition of the waterpipe should occur outdoors in better air quality environments. This study also re-emphasises previous observations that including waterpipe premises in smokefree laws does not necessarily guarantee self-compliance, and resources are needed to enforce these laws. In doing so, cultural sensitivities need to be taken into account to promote participation with waterpipe premises in Western countries. This study also highlights that waterpipe premises should not solely remain a focus of tobacco control specialists; rather public health practitioners should take an interest in infection control measures and other agencies should remain attentive to these working environments. Meanwhile, staff working in waterpipeserving premises should be targeted for cessation interventions services as has been documented for other occupational hazards where smoking is commonplace (Pimple et al., 2012).

In conclusion, waterpipe premises are deep-rooted in culture and their employees are a hard-to-reach group with important occupational health hazards that are of potential concern. Occupational health is a neglected area of waterpipe tobacco research. It is likely that the smokefree law is not offering the waterpipe premise employee protection that it was originally intended for. Health hazards are mainly centred on chronic smoke exposure and employee requirements to draw puffs from the waterpipe. Meanwhile, efforts should focus on promoting cultural engagement and integration in order to ameliorate future surveillance of these premises.

\section{Acknowledgements}

Thanks to waterpipe premises employees for their general interest in this research.

\section{References}

Action On Smoking And Health (Ash) 2011. Smokefree legislation [online] Available at: http://ash.org.uk/files/ documents/ASH_119.pdf [Date of access 24 April 2014].

Akl E, Jawad M, Lam W, et al (2013). Motives, beliefs and attitudes towards waterpipe tobacco smoking: a systematic review. Harm Reduct J, 10, 12.

Akl EA, Gaddam S, Gunukula SK, et al (2010). The effects of waterpipe tobacco smoking on health outcomes: A systematic review. Int J Epidemiol, 39, 834-57.

Al-Naggar RA, Saghir FSA (2011). Water pipe (Shisha) smoking and associated factors among Malaysian university students. Asian Pac J Cancer Prev, 12, 3041-7.

Amin TT, Monem MA, Zaza BO, Suleman W. (2010). Harm perception, attitudes and predictors of waterpipe (Shisha) smoking among secondary school adolescents in Al-Hassa, Saudi Arabia. Asian Pac J Cancer Prev, 11, 293-301.

Barnett TE, Curbow BA, Soule EK, Tomar SL, Thombs DL (2011). Carbon monoxide levels among patrons of hookah cafes. Am J Prev Med, 40, 324-328.

Bbc News Lancashire (2011). Blackburn shisha-smoker in blowtorch blast [online]. Available at: http://www.bbc.co.uk/ news/uk-england-lancashire-12456810 [Date of access 24 April 2014].

British Heart Foundation (2012). Rise in 'shisha bars' prompts warning on dangers of waterpipe smoking [online]. Available at: http://www.bhf.org.uk/default.aspx?page=14417. [Date of access 29 June 2013] [Online]. Available: http://www. bhf.org.uk/default .aspx?page $=14417$.

Clarke SFJ, Stephens C, Farhan M, et al (2012). Multiple patients with carbon monoxide toxicity from water-pipe smoking. Prehospital Dis Med, 27, 612-4.

Cobb CO, Vansickel AR, Blank MD, et al (2013). Indoor air quality in Virginia waterpipe cafes. Tobacco Control, 22, $338-43$.

Deshpande A, Kudtarkar P, Dhaware D, Chowgule R (2010). Study of secondhand smoke levels pre and post implementation of the comprehensive smoking ban in mumbai. Indian J Comm Med, 35, 409-13.

Eissenberg T, Shihadeh A (2009). Waterpipe Tobacco and Cigarette Smoking. Direct Comparison of Toxicant Exposure. Am J Prev Med, 37, 518-23.

Fromme H, Dietrich S, Heitmann D, et al (2009). Indoor air contamination during a waterpipe (narghile) smoking session. Food Chemical Toxicol, 47, 1636-41.

Griffiths P, Gossop M, Powis B, Strang J (1993). Reaching hidden populations of drug users by privileged access interviewers: methodological and practical issues. Addict, 88, 1617-26.

Hammal F, Chappell A, Wild TC, et al (2013). 'Herbal' but potentially hazardous: an analysis of the constituents and smoke emissions of tobacco-free waterpipe products and the air quality in the cafes where they are served. Tob Control.

Hsieh HF, Shannon SE (2005). Three approaches to qualitative content analysis. Qualitative Health Res, 15, 1277-88.

Jawad, M. (2013a). Malaysia: waterpipe tobacco smoking declared 'haram' in worldwide news and comment. Tob Control, 22, 292.

Jawad M (2013b). The public health implications of shisha smoking in london. in: department of primary care and public health, i.c. l. (ed.). Westminster Adult Services and Health Policy and Scrutiny Committee.

Jawad M (2014). Legislation enforcement of the waterpipe tobacco industry: a qualitative analysis of the London experience. Nicotine Tob Res, 16, 1000-8

Jawad M, Wilson A, Lee JT, et al (2013). Prevalence and predictors of water pipe and cigarette smoking among secondary school students in London. Nicotine Tob Res, 15, 2069-75.

Jorgensen DL (1989). (Ed) Participant observation: a methodology for human studies (Vol 15). Sage.

Kassim S,Al-Bakri A,Al'absi M, Croucher R (2014). Waterpipe tobacco dependence in u.k. male adult residents: a crosssectional study. Nicotine Tobacco Res, 16, 316-25.

King BA, Dube SR, Ko JY (2011). Secondhand smoke concentrations in hospitality venues in the pacific basin: findings from American Samoa, Commonwealth of the Northern Mariana Islands, and Guam. Asian Pac J Cancer Prev, 12, 2881-5.

Knishkowy B, Amitai Y, 2005. Water-pipe (narghile) smoking: an emerging health risk behavior. Pediatrics, 116, 113-9.

Martinasek MP, Mcdermott RJ, Martini L (2011). Waterpipe (hookah) tobacco smoking among youth. Curr Probl Pediatr Adolesc Health Care, 41, 34-57.

Monn C, Kindler P, Meile A, Brandli O (2007). Ultrafine particle emissions from waterpipes. Tobacco Control, 16, 390-3.

Munckhof WJ, Konstantinos A, Wamsley M, Mortlock M, Gilpin C (2003). A cluster of tuberculosis associated with use of a marijuana water pipe. Int $J$ Tuberculosis Lung Disease, 7, 860-5.

Noonan, D. 2010. Exemptions for hookah bars in clean indoor air legislation: a public health concern. Public Health Nursing, 
27, 49-53.

Pimple S, Pednekar M, Mazumdar P, Goswami, S, Shastri S. (2012). Predictors of quitting tobacco-results of a worksite tobacco cessation service program among factory workers in Mumbai, India. Asian Pac J Cancer Prev, 13, 533-8.

Rastam S, Ward Kd, Eissenberg T, Maziak W (2004). Estimating the beginning of the waterpipe epidemic in Syria. BMC public health, 4, 1-5.

Raute LJ, Gupta PC, Pednekar, MS (2011). Smoking ban and indoor air quality in restaurants in Mumbai, India. Indian $J$ Occup Environ Med, 15, 68-72.

Shihadeh A, Salman R, Jaroudi E, et al (2012). Does switching to a tobacco-free waterpipe product reduce toxicant intake? A crossover study comparing $\mathrm{CO}, \mathrm{NO}, \mathrm{PAH}$, volatile aldehydes, " tar" and nicotine yields. Food Chemical Toxicol, 50, 1494-8.

Zulkifli A, Abidin NZ, Abidin EZ, et al (2014). Implementation of smoke-free legislation in Malaysia: are adolescents protected from respiratory health effects? Asian Pac J Cancer Prev, 15, 4815-21. 